\title{
Efeitos de um ciclo de modelagem no contexto do ensino de Física
}

\author{
Ednilson Sergio Ramalho de Souza ${ }^{1}$ \\ Instituto de Ciências da Educação - Universidade Federal do Oeste do Pará \\ Santarém - PA
}

\section{Resumo}

O objetivo deste artigo é compreender efeitos proficuos e percalços da modelagem matemática na visão de professores de física. Para isso, com fundamento em Hestenes (1987; 2010), Heidemann (2015), Souza (2018) foi desenvolvido um ciclo de modelagem sobre o tema Poluição Sonora organizado didaticamente em oito ações. A pesquisa de campo envolveu a metodologia mista com foco em interpretações quantitativas $e$ qualitativas. Os colaboradores da pesquisa foram treze $(n=13)$ professores de física em formação de um curso de licenciatura integrada em matemática e física de uma universidade pública no município de Almeirim, Pará, Brasil. Os resultados sugerem que os professores conceberam a modelagem como importante no contexto do ensino de física, especialmente para alcançar determinados conteúdos conforme a grade curricular da disciplina, para o uso de processos científicos durante a construção de modelos matemáticos e para a promoção de discussões e de debates em sala de aula. Por outro lado, eles relataram dificuldades para definir objetivos de pesquisa a partir de temas da realidade e para construir modelos matemáticos constituídos por múltiplas ferramentas de representação.

Palavras-chave: Efeitos Profícuos e Percalços; Ciclo de Modelagem; Ensino de Física.

\footnotetext{
${ }^{+}$Effects of a modeling cycle in the context of physics teaching

* Recebido: abril de 2020. Aceito: outubro de 2020.

${ }^{1}$ E-mail: ednilson.souza@ufopa.edu.br
} 


\begin{abstract}
The aim of this article is to understand the fruitful effects and perishments of mathematical modeling in the view of physics teachers. For this, based on Hestenes (1987; 2010), Heidemann (2015), Souza (2018) was developed a modeling cycle on the theme Noise Pollution organized didactically in eight actions. The field research involved the mixed methodology focusing on quantitative and qualitative interpretations. The research collaborators were thirteen $(n=13)$ physics teachers in the formation of an integrated degree course in mathematics and physics at a public university in the municipality of Almeirim, Pará, Brazil. The results suggest that teachers conceived modeling as important in the context of physics teaching, especially to achieve certain contents according to the curriculum of the discipline, for the use of scientific processes during the construction of mathematical models and for the promotion of discussions and debates in the classroom. On the other hand, they reported difficulties to define research objectives based on themes of reality and to build mathematical models consisting of multiple representation tools.
\end{abstract}

Keywords: Fruitful Effects and Perishes; Modeling Cycle; Physics Teaching.

\title{
I. Olhar inicial
}

A história da ciência mostra que ao menos desde o século XVI que a modelagem matemática vem sendo utilizada sistematicamente como método científico, a exemplo de cientistas notáveis como Galilei Galileu e Isaac Newton. No entanto, somente a partir do século XX é que ela foi percebida como constituinte importante na construção do pensamento científico, como podemos inferir das reflexões de filósofos contemporâneos como Mario Bunge (1974/2013) e Ronald Giere (2004). Em suas reflexões, esses filósofos argumentam que a construção de modelos teóricos (modelos matemáticos) é necessária porque não temos acesso direto ao mundo físico, tal acesso é sempre parcial e limitado pelo poder preditivo de tais modelos. Desse modo, a filosofia da modelagem matemática tem possibilitado nos últimos quarenta anos profícuas discussões sobre ensino de ciências/física.

A modelagem matemática começou a fazer parte da educação científica de forma mais acentuada por volta dos anos 1970. Foi nesse período que o filósofo argentino Mario Bunge publicou uma teoria de modelagem científica (BUNGE, 1974/2013) que serviu de base à elaboração de uma teoria cognitiva de modelagem por David Hestenes (1987). Por sua vez, a teoria de Hestenes impulsionou o surgimento de uma didática atualmente bastante utilizada 
na formação de professores de física norteamericanos, a modeling instruction ${ }^{2}$, ou, como vem se popularizando aqui no Brasil, o chamado ciclo de modelagem de Hestenes (HEIDEMANN, ARAÚJO e VEIT, 2012).

No Brasil, a pesquisa sobre modelagem matemática no ensino de física é mais recente. Um dos artigos pioneiros foi o de Veit e Teodoro (2003) ao discutirem sobre a importância do uso do software modellus em conexão com os PCNEM (Parâmetros Curriculares Nacionais para o Ensino Médio). Na última década, embora de maneira moderada, constata-se que a modelagem tem sido tema de interesse crescente em artigos, dissertações e teses sobre o ensino brasileiro de física, como ilustra a figura que segue.

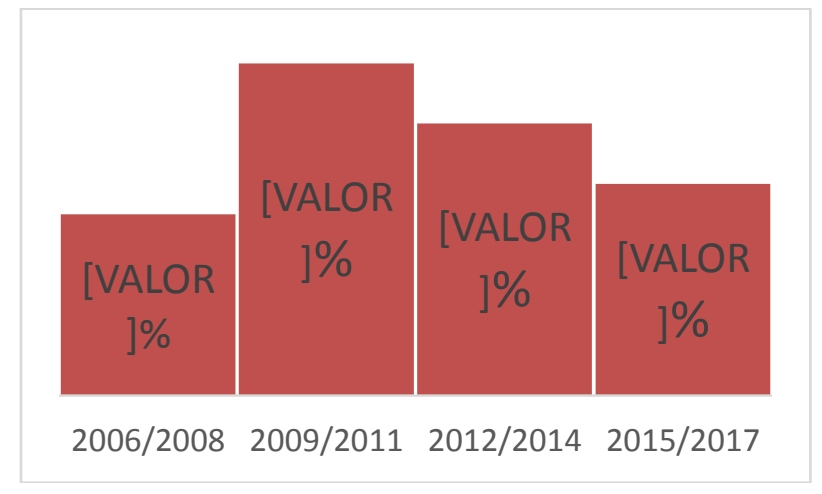

Fig. 1 - Publicações sobre modelagem matemática no ensino de física (2006/2017).

Fonte: Souza (2018).

Para elaboração da Fig. 1 usou-se os marcadores "modelagem matemática" + "ensino de física" como palavras-chave de busca na internet. Escolheu-se a internet de uma forma geral para "garimpar" os dados e não os repositórios da Biblioteca Digital Brasileira de Teses e de Dissertações (BDTD) porque objetivou-se fazer um levantamento geral de trabalhos publicados, inclusive artigos científicos em periódicos e em eventos sobre a temática.

A partir do resultado, selecionou-se trabalhos em que a preocupação dos autores fosse lançar discussões práticas ou teóricas sobre o processo de construção de modelos matemáticos como meio para compartilhar conhecimentos em física. Desse modo, foram retirados do corpus de análise os trabalhos em que, apesar de haver construção de modelos matemáticos, esta construção não se destinava deliberadamente à aprendizagem de algum conceito, procedimento ou atitude em física. Assim, sem qualquer pretensão de exaustão, selecionou-se 34 trabalhos publicados em anais de congressos, repositórios digitais de universidades e de revistas científicas.

Desse modo, a Fig. 1 ilustra as frequências de trabalhos publicados no período de 2006 a 2017 sobre ensino de física com modelagem matemática. Destaca-se que o período de

\footnotetext{
2 Refiro-me à didática modeling instruction, proposta pelo grupo de pesquisa de David Hestenes e que, conforme esclarece a AMTA (American Modeling Teachers Association), tem contribuído grandemente para a reformulação do ensino de ciências norteamericano.
} 
maior produção foi o de 2009/2011 com 11 (33,3\%) trabalhos publicados. Logo em seguida, o período de 2012/2014 com 09 (27,3\%) trabalhos publicados. Talvez, as discussões sobre modelagem matemática ocorridas em eventos científicos nacionais e internacionais, como a CNMEM (Conferência Nacional sobre Modelagem na Educação Matemática), tenham contribuído para o número elevado de trabalhos publicados nesses dois períodos. Por outro lado, nota-se que no período de 2015/2017 houve 07 (21,2\%) trabalhos publicados e no período de 2006/2008 houve 06 (18,2\%) trabalhos publicados, sendo este o período de menor produção na área. No entanto, em todos os anos do período compreendido entre 2006/2017 houve a publicação de pelo menos 01 trabalho. Embora a pesquisa não seja exaustiva e os números sejam relativamente baixos, eles sugerem o interesse crescente de pesquisadores brasileiros nessa linha emergente de pesquisa na grande área ensino de ciências.

Visando a uma análise um pouco mais aprofundada, a figura a seguir ilustra a frequência acadêmico-regional de trabalhos publicados sobre a temática.

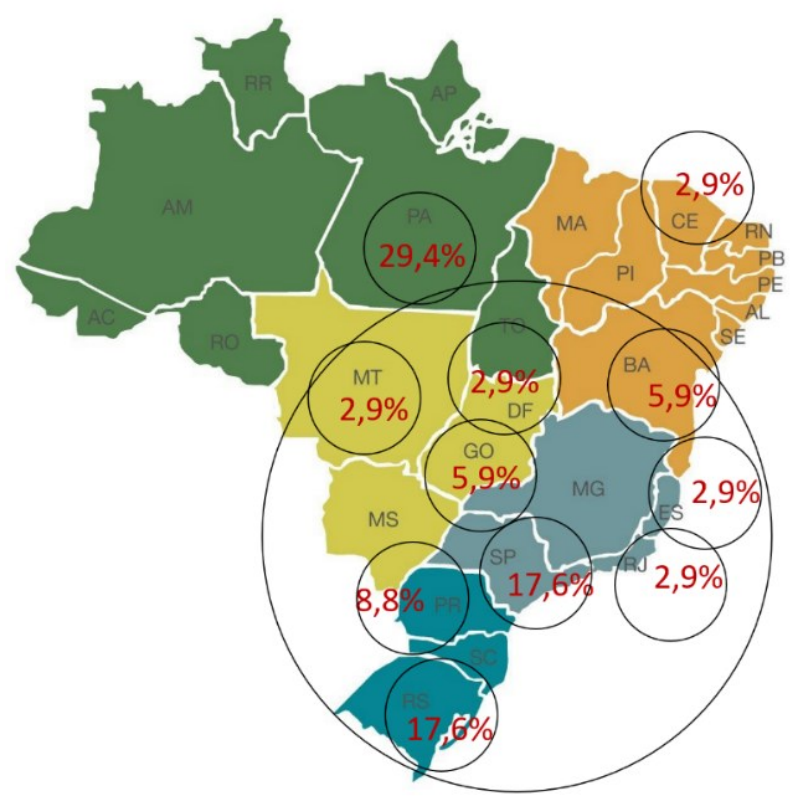

Fig. 1 - Distribuição acadêmico-regional de trabalhos publicados sobre ensino de fisica com modelagem matemática. Fonte: Souza (2018).

A visão acadêmico-regional na Fig. 2 é importante para apontar focos de produção e indicar onde estão os coletivos de pensamento (FLECK, 2010) sobre modelagem matemática no ensino de física. Observam-se onze (11) círculos esotéricos distribuídos em todas as cinco regiões brasileiras (Norte, Nordeste, Centro-Oeste, Sudeste e Sul). Destaca-se que o Estado do

\footnotetext{
3 Um coletivo de pensamento pode ser entendido como constituído de um grupo esotérico de pessoas responsáveis por divulgar, por meio de interação coercitiva, determinado estilo de pensamento e por um grupo exotérico mais abrangente, embora com menos força coercitiva, também colaboram para a divulgação do coletivo de pensamento (FLECK, 2010).
} 
Pará alcançou a maior frequência de produções, com taxa de 29,4\%. Os Estados de São Paulo e Rio Grande do Sul vêm em seguida, ambos com taxa de 17,6\%. Depois, o Estado do Paraná, com taxa de 8,8\%. Os Estados da Bahia e de Goiás, ambos com taxa de 5,9\%, aparecem em seguida. Por fim, todos com taxa de 2,9\%, surgem os Estados do Ceará, Espírito Santo, Rio de Janeiro, Mato Grosso e o Distrito Federal.

Destaca-se que a parte centro-sul do Brasil, pela relativa proximidade geográfica, pode ser vista como um grande coletivo plural de pensamento em modelagem matemática no ensino de física, podendo gerar novos círculos esotéricos e exotéricos pela irradiação das ideias para as demais regiões do país. Contudo, esse coletivo de pensamento centro-sul não é hegemônico, uma vez que, pela relativa distância geográfica, existem círculos esotéricos importantes à margem dele, é o caso do Pará e do Ceará. Essas reflexões, sugerem que ainda não é possível desenhar um programa de pesquisa nacional para o tema. Isso seria salutar para impulsionar discussões acadêmicas sobre as pesquisas realizadas. Nesse sentido, comenta-se a seguir sobre algumas dessas pesquisas.

Moutinho (2007) realizou pesquisa de mestrado com 32 professores em formação a fim de saber de que maneira a abordagem CTS (Ciência-Tecnologia-Sociedade) e a modelagem matemática poderiam ajudar na formação diferenciada de um professor de física. A partir da frase de Arquimedes "deem-me uma alavanca e um ponto de apoio e deslocarei o mundo" foram feitos experimentos sobre alavancas a fim de resolver o problema de como deslocar o mundo. Em suas reflexões, o autor relata que o ambiente gerado pela interação da abordagem CTS com a modelagem matemática, auxiliados pela experimentação, foi favorecedor para a formação de um professor que queira dar significado ao processo de ensino e de aprendizagem. Considera-se essa pesquisa importante ao propor um enlace entre modelagem matemática, educação CTS e experimentação.

Nessa esteira, Batista (2009) contou com experimentos sobre eletricidade ao usar a modelagem matemática em conjunto com a experimentação com 19 estudantes do nono ano do ensino fundamental visando discuti-la como ambiente que conduz a uma aprendizagem efetiva dos conteúdos de matemática e de física. $\mathrm{O}$ autor reforça que a estratégia utilizada possibilitou um aprendizado eficiente e participativo, em que os estudantes foram capazes de fazer conexões entre a física, a matemática e as situações cotidianas. Além disso, a estratégia promoveu a interdisciplinaridade e contribuiu para a formação sociopolítica dos estudantes, contribuindo para o exercício da cidadania. Percebe-se, nas reflexões do autor, o potencial que a modelagem matemática possui para desenvolver competências para o letramento científico, tanto nas aulas de física quanto nas aulas de matemática; não obstante, não foram realizadas maiores discussões nesse sentido.

Souza (2012) usou a modelagem matemática com ênfase em problemas da realidade com 24 acadêmicos de um curso de matemática durante uma disciplina de física fundamental. Os temas escolhidos foram "Aumento de temperatura" e "Compra de carros". Após discussões sobre os temas, os grupos de estudantes buscaram elaborar modelos matemáticos 
para investigar as seguintes questões: qual o condicionador de ar ideal para refrigerar determinado ambiente? Qual o carro ideal para comprar considerando a relação custo $\mathrm{x}$ benefício? Durante as investigações, os acadêmicos recorreram a pesquisas de campo junto a oficinas de refrigeração e a vendedores de carro da cidade. Também realizaram pesquisas na internet, em livros e em revistas científicas. Foram mobilizados conceitos sobre calor, temperatura, unidade BTU (British thermal unit), velocidade, aceleração, força, potência e torque. Verificou-se que os estudantes se sentiram motivados e que houve experiências interdisciplinares. Contudo, para que a compreensão conceitual pudesse ser consolidada, ressalta o autor, houve a necessidade de aprofundamentos por meio de resolução de problemas. Essa pesquisa é interessante porque ressalta que a construção per si de modelos matemáticos, isto é, sem que haja certa preocupação no aprofundamento conceitual, pode não garantir aprendizagem consubstanciada sobre o conhecimento em física.

Ao investigar a relação entre os modelos matemáticos produzidos por estudantes durante a realização de atividades experimentais e os modelos prescritos nos manuais técnicos, Silva Neto (2015) propõe, a partir da ideia de ciência normal de Thomas Kuhn, uma abordagem pela comparação entre modelo experimental e modelo teórico mediado pela modelagem matemática. $\mathrm{Na}$ aplicação dessa proposta, o autor identificou que estudantes de cursos de engenharia e de ciências naturais de uma universidade federal sentiram dificuldades para organizar as informações em relações conceituais complexas e que os modelos matemáticos produzidos por eles geralmente não alcançaram o mesmo grau de refinamento dos modelos matemáticos dos manuais técnicos. Apesar disso, a abordagem mostrou-se apropriada para ensino e para a aprendizagem de conteúdos de disciplinas experimentais de física. Entende-se que essa pesquisa é relevante ao mostrar o impacto cognitivo da modelagem matemática na aprendizagem em física mediado pela experimentação, reforçando, portanto, as inferências de Moutinho (2007) e de Batista (2009).

Percebe-se que o ensino de física com modelagem matemática, dentre outras possibilidades, pode favorecer a formação de cidadãos críticos e reflexivos, pode suscitar a motivação, a contextualização e a interdisciplinaridade, pode promover a compreensão conceitual, pode contribuir para a aquisição de habilidades experimentais e investigativas. Contudo, percebe-se certa carência de pesquisas que focalizem as percepções de professores de física em formação. Nessa direção, o objetivo deste artigo é analisar potencialidades e desafios de um ciclo de modelagem na visão de futuros professores dessa disciplina.

Assim, na seção que segue, apresenta-se a metodologia da pesquisa em que se procurou aproximação com a abordagem mista. Em seguida, discute-se sobre fatores profícuos e percalços a partir do que relatam professores de física inseridos em um ciclo de modelagem sobre o tema Poluição Sonora. Finaliza-se o artigo com reflexões sobre consequências do estudo ao ensino brasileiro de física. 


\section{II. $O$ ciclo de modelagem de Hestenes}

De um ponto de vista procedimental, o ciclo de modelagem de Hestenes pode ser organizado em dois estágios básicos: elaboração do modelo e implementação do modelo, conforme ilustra-se na Fig. 3.

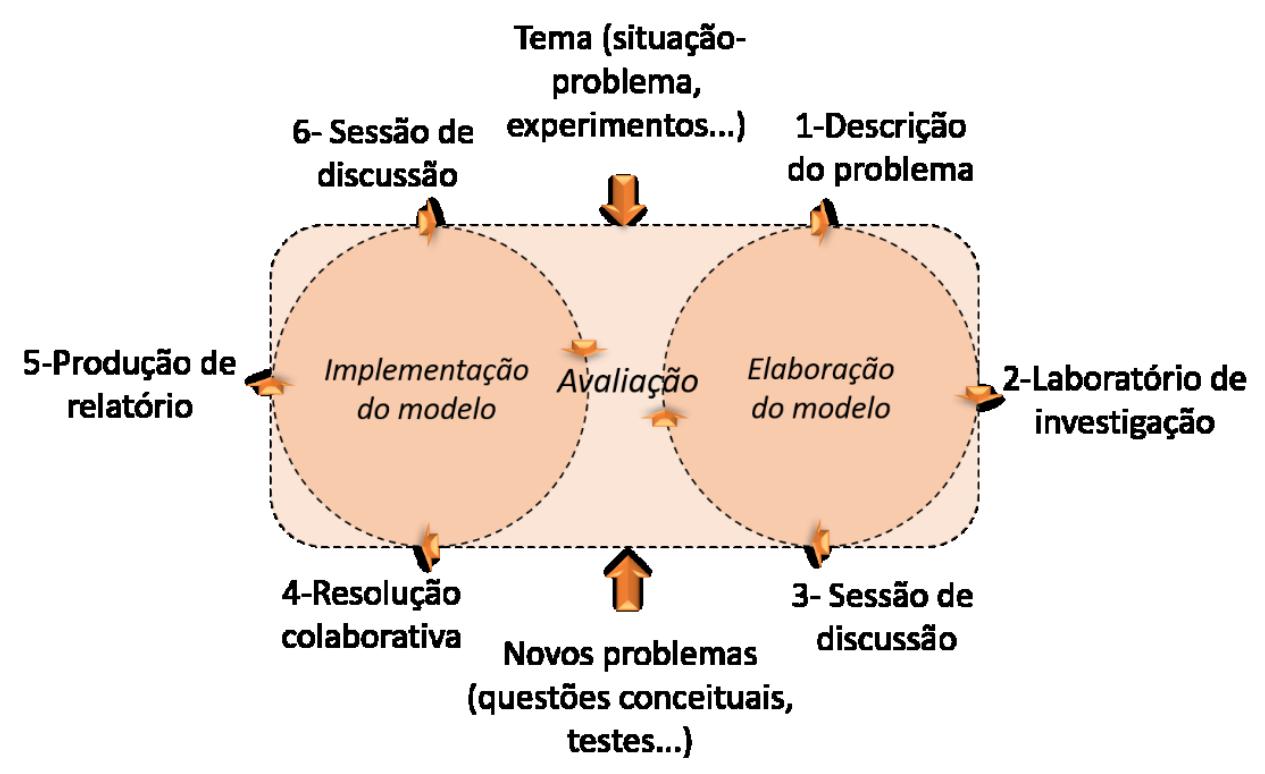

Fig. 3 - O ciclo de modelagem de Hestenes. Fonte: Souza (2018).

$\mathrm{Na}$ Fig. 3, apresenta-se um esquema para o ciclo de modelagem de Hestenes. No primeiro estágio, ocorre a elaboração de um modelo matemático a partir de um problema comum aos grupos. No segundo estágio, ocorre a implementação da estrutura epistêmica do modelo matemático por meio da resolução colaborativa de problemas diversos. Cada um desses estágios possui subetapas com características distintas a serem realizadas pelos estudantes sob orientação docente. A seguir, serão delineadas discussões sobre cada um desse momentos.

\section{II.1 Elaboração do modelo}

De acordo com o esquematizado na Fig. 3, o primeiro estágio do ciclo de modelagem, elaboração do modelo, inicia com a descrição do problema. O problema pode ser proposto pelo professor ou pelos grupos de estudantes. O importante é que seja atendido tanto os objetivos pedagógicos quanto o interesse dos estudantes pelo tema de pesquisa. Um problema é entendido próximo à concepção de Dante (2011), isto é, trata-se de uma situação que os estudantes precisam resolver, contudo, não dispõem imediatamente de um caminho rápido e direto que leve à solução. Nesse norte, um autêntico problema é diferente de um exercício. No primeiro, os estudantes possuem certas habilidades e cognição, mas não são suficientes para propor um caminho ao enfrentamento, isto é, eles devem investigar 
possibilidades de soluções. No segundo, os estudantes possuem certas habilidades e cognição suficiente para propor soluções ao problema, embora, geralmente, ainda tenham que recorrer a pesquisas para consolidar suas investigações. Para resolver um problema em física, os estudantes podem levantar questionamentos, fazer hipóteses e delinear o desenvolvimento de um modelo matemático, no caso do exercício, eles já conhecem o modelo matemático a ser aplicado.

Heidemann (2015) ressalta que o momento inicial do ciclo de modelagem de Hestenes pode ser contextualizado de diferentes maneiras: "[...] podendo ser explorados vídeos, simulações computacionais, experimentos de laboratório etc. (p. 41).

Ademais, Heidemann observa que um ciclo de modelagem não necessariamente começa pelo estágio de elaboração do modelo.

Além disso, ao contrário de iniciar pela exposição de uma situação física para que os estudantes explorem e construam um modelo teórico com o intuito de descrevêlo, o ciclo pode começar com a apresentação de um modelo teórico, cabendo aos alunos avaliar a sua adequação para descrever uma determinada situação. $O$ essencial é que o problema envolva o uso de habilidades e ferramentas de modelagem [...] (HEIDEMANN, 2015, p. 41-42).

Essa flexibilidade no desenvolvimento de um ciclo de modelagem deixa o professor livre para iniciar a atividade pelo estágio de implementação do modelo. Contudo, é necessário explicitar que essa implementação não quer dizer substituição de valores numéricos em uma equação matemática. Nesse caso, os estudantes terão a tarefa de investigar se o modelo matemático é apropriado ou não para analisar determinada situação física, poderão investigar seu limite de validade, sua aplicabilidade, sua importância sociocultural, econômica, histórica.

O objetivo principal da descrição do problema é evidenciar princípios, leis, teorias físicas, variáveis e constantes; ou seja, grandezas físicas que se inter-relacionam no contexto da situação enfrentada. Hestenes (1987) argumenta que a descrição de um sistema é norteada por alguma teoria científica, pois é a teoria que especifica quais tipos de objetos e de propriedades podem ser modelados e quais tipos de modelos podem ser desenvolvidos. $\mathrm{O}$ apogeu do momento de descrição do problema é um conjunto de conceitos, de procedimentos, de atitudes que poderão ser utilizados no momento do laboratório de investigação.

Para iniciar o momento de laboratório de investigação, a classe é organizada em grupos pequenos de três a cinco componentes (grupos colaborativos). A palavra laboratório não deve ser entendida como um ambiente fechado cheio de equipamentos técnicos especializados, mas um momento em que serão planejadas e realizadas atividades que envolverão a observação de campo, a experimentação, a prática de determinada arte ou habilidade, enfim, os erros e os acertos.

Heidemann (2015) chama atenção que no momento de investigação laboratorial: 
Em pequenos grupos, os alunos trabalham no planejamento e na condução de experimentos para responder ou esclarecer o problema proposto [...]. Durante essa etapa, os professores devem estar preparados para introduzir novas ferramentas de representação na medida em que os alunos estiverem preparados para fazer bom uso delas. [...] é necessário dar-se maior atenção ao papel crítico do tipo de representação no desenvolvimento da compreensão física. Deve-se reconhecer que a habilidade de modelar, e assim compreender, depende das ferramentas disponíveis (equações, gráficos, tabelas, diagramas etc.). Portanto, é preciso que as atividades sejam projetadas para auxiliar os estudantes a desenvolverem habilidades associadas ao uso de tais ferramentas (HEIDEMANN, 2015, p. 42).

No ciclo de modelagem, o laboratório de investigação envolve produção e discussão de dados qualitativos e de dados quantitativos pelos próprios estudantes sob orientação docente; envolve discussões para o planejamento de procedimentos necessários e o levantamento de informações em fontes diversas (internet, livros, entrevistas, visitas de campo, experimentos). O clímax do laboratório de investigação é um conjunto de informações que deve ser logicamente coordenado em um modelo matemático fazendo-se uso de múltiplas ferramentas de representações. Por fim, os modelos matemáticos são registrados nos whiteboards utilizando-se marcadores de diferentes cores.

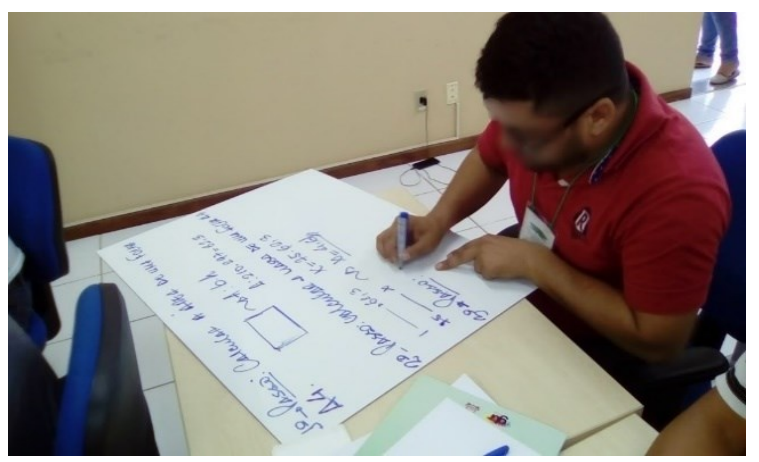

Fig. 4 - Produção de um whiteboard em um ciclo de modelagem. Fonte: Souza (2018).

A Fig. 4 mostra a produção de um Whiteboard, trata-se de pequenos quadros brancos de aproximadamente $80 \mathrm{~cm}$ por $60 \mathrm{~cm}$ que auxiliam na argumentação científica durante a defesa dos modelos matemáticos elaborados pelas equipes. Desse modo, cada whiteboard sistematiza um modelo matemático (ou parte dele) que será defendido e discutido coletivamente pela classe no decorrer da última fase do estágio de elaboração do modelo: a primeira sessão de discussão.

Na primeira sessão de discussão, as equipes apresentam seus modelos matemáticos e justificam procedimentos e raciocínios. Heidemann (2015) chama a atenção que nesse momento: 
[...] os alunos apresentam e justificam as suas conclusões na forma oral e escrita. Para isso, utilizam as mais diversas ferramentas de representação destacando-as em seus quadros-brancos [...]. Com isso, busca-se aprimorar a habilidade de argumentação dos alunos e a qualidade de seus discursos. Durante essa etapa, é importante se estabelecer um clima de abertura e respeito em que cada estudante se sinta incentivado a participar. O professor assume o papel de mediador e fica atento às principais concepções alternativas que os alunos externalizam sobre os conteúdos de física abordados. Esses equivocos são discutidos com os estudantes, que são convidados a explicitar suas ideias e raciocínios de modo que, a partir de suas contribuições, se estabeleçam as bases para o compartilhamento de significados entre os participantes do processo de ensino-aprendizagem. (HEIDEMANN, 2015, p. 43).

Assim, o professor assume a importante tarefa de orientar os discursos dos estudantes de modo a fazer com que insiram suas justificativas em teorias e em leis físicas, sendo que os whiteboards servem de âncoras para tal inserção. Isso possibilita que os estudantes reformulem seus modelos mentais quando associados a múltiplas ferramentas de representação em meio a explicações, justificativas, previsões (HETENES, 2010).

Importante ressaltar que a sessão de discussão não consiste na mera apresentação de pesquisas realizadas pelos grupos como culminância da atividade de modelagem matemática. Para além disso, é um momento fundamental do ciclo de modelagem de Hestenes em que os estudantes são questionados de tal maneira que justifiquem com fundamento científico procedimentos e raciocínios mobilizados na elaboração do modelo matemático. É um momento em que a argumentação científica concorre para melhorar a compreensão por meio da reformulação de modelos mentais inconsistentes. O professor age no sentido de direcionar perguntas aos grupos colaborativos por meio de técnicas de pedagogia argumentativa, é o chamado discurso de modelagem. Com apoio dos modelos matemáticos registrados nos whiteboards, cada grupo defende as razões que os levaram a usar tal conceito, a realizar determinado experimento ou pesquisa de campo, a tomar determinada decisão ou atitude.

Nesse processo argumentativo, conforme os modelos matemáticos vão sendo compartilhados pelos grupos, as discussões entre os pontos convergentes e os pontos divergentes permitem compreensão comum sobre a estrutura epistêmica do modelo, que será aprofundada no próximo estágio do ciclo de modelagem: a implementação do modelo.

\section{II.2 Implementação do modelo}

Conforme esquematizado na Fig. 3, o segundo estágio do ciclo de modelagem de Hestenes, implementação do modelo, inicia com a resolução colaborativa de problemas. Problemas esses que suscitem a estrutura epistêmica do modelo matemático desenvolvido no estágio anterior. Nesse sentido, podem-se utilizar problemas adaptados do livro-texto, testes de múltipla escolha, questões conceituais, experimentos de baixo custo ou de laboratório experimental, simulações computacionais etc. Importante ressaltar que não se trata de uma 
lista enfadonha de exercícios, mas preza-se pela qualidade de poucos problemas a serem investigados colaborativamente pelos grupos.

Heidemann (2015), comenta que no momento de implementação do modelo:

[...] os estudantes utilizam o modelo recém-explorado em novas situações para refinar e aprofundar a sua compreensão. Os estudantes trabalham em problemas desafiadores em pequenos grupos, e depois apresentam e defendem seus resultados para a classe por meio dos quadros brancos. Essa fase inclui questionários, testes, trabalhos em laboratório, implementação computacional etc. (HEIDEMANN, 2015, p. 43).

As atividades de implementação do modelo são importantes porque os estudantes aprofundam compreensões ao ramificarem sua estrutura epistêmica na análise de aspectos físicos do fenômeno investigado. Hestenes (1987), sublinha que a ramificação é um processo principalmente matemático e é importante para se trabalhar propriedades e implicações especiais do modelo. Por exemplo, no caso da mecânica newtoniana, equações de movimento são resolvidas para determinar trajetórias com várias condições iniciais, resultados são representados e analisados analiticamente e graficamente. Quando existe necessidade e condições apropriadas, o modelo matemático é validado pela avaliação empírica.

Para sistematizar por escrito as soluções dos problemas de implementação do modelo, as equipes produzem relatórios em que organizam suas respostas envolvendo os conteúdos (conceituais, procedimentais e atitudinais) e as discussões críticas. O relatório é relevante como forma de incentivar a produção textual coletiva entre os integrantes do grupo colaborativo. Além disso, a produção grupal dos relatórios possibilita que os estudantes aprofundem compreensões ao terem que pesquisar e discutir sobre conceitos e procedimentos que consideram relevantes de serem expostos no texto escrito. Nesse sentido, a produção do relatório é geradora de debates e de reflexões entre os integrantes de uma mesma equipe, possibilitando profundas discussões.

Na segunda sessão de discussão, os grupos colaborativos resumem as respostas aos problemas de implementação do modelo e defendem as resoluções, justificando procedimentos e pensamentos com argumentos científicos. Novamente, o professor assume a importante tarefa de orientar o discurso de modelagem de modo a fazer com que os estudantes insiram suas justificativas em teorias e em leis físicas. Wells, Hestenes e Swackhamer (1995) propõem como forma de motivar episódios argumentativos que os relatórios sejam redistribuídos entre os grupos colaborativos de modo a fazer com que uma equipe avalie criticamente as soluções de outra equipe. Conforme as soluções dos problemas vão sendo compartilhadas e refinadas, a estrutura epistêmica do modelo matemático ganha novos significados, que favorecem compreensões e aplicações em novas situações.

Resta dizer que a avaliação de aprendizagem no ciclo de modelagem é formativa. $\mathrm{O}$ professor pode checar de alguma maneira a aprendizagem individual dos estudantes e decidir em resolver outros problemas ou iniciar novo ciclo para o estudo de outro campo conceitual. 
Nesse sentido, o portfólio de aprendizagem pode ser utilizado com bons resultados avaliativos. Ambrósio (2013) argumenta que o portfólio consiste de uma coleção de trabalhos realizados pelos estudantes que permite acompanhar seus desenvolvimentos por meio de diferentes formas de análise, de avaliação, de execução e de apresentação de produções desencadeadas nas ações de ensino e de aprendizagem realizadas num determinado espaçotempo. Nesse processo, o estudante guarda suas produções, produções essas que mostram pistas, evidências, vestígios dos conceitos, dos fatos, dos procedimentos e das atitudes desenvolvidas durante um tempo mediado pelo docente.

A seguir, descreve-se a metodologia da pesquisa de campo e o desenvolvimento de um ciclo de modelagem sobre Poluição Sonora.

\section{Trilhas metodológicas}

A pesquisa de campo foi orientada por procedimentos da metodologia mista, em que houve enfoque tanto em técnicas qualitativas quanto em técnicas quantitativas. Creswell e Clark (2013) pontuam algumas características importantes de métodos mistos, dentre os quais destaca-se: o pesquisador coleta e analisa rigorosamente, com base no objetivo da pesquisa, tanto os dados qualitativos quanto os dados quantitativos; ele mistura (integra ou vincula) as duas formas de dados concomitantemente, fazendo um construir o outro ou incorporando um no outro, contudo, pode priorizar uma ou outra forma de dados.

Os sujeitos participantes foram treze $(n=13)$ professores de física em formação. Importante ressaltar que, embora eles já fossem professores atuantes no ensino fundamental menor do município de Almeirim-PA, ainda não possuíam a licenciatura em física. Nesse cenário, à época da pesquisa, estavam cursando uma disciplina de estágio I sob orientação do autor deste artigo como componente curricular de uma licenciatura integrada em matemáticafísica de uma universidade pública federal pelo Plano Nacional de Formação de Professores da Educação Básica (PARFOR).

Conquanto os sujeitos da pesquisa já fossem professores do ensino fundamental menor, eles participaram dos ciclos de modelagem no "modo aluno", na condição de futuro professor de física. Considera-se que realizar pesquisas em que os professores em formação ocupem o lugar de seus futuros alunos é importante para motivá-los a entrar em contato com propostas pedagógicas alternativas ao método bancário (FREIRE, 2005); uma vez que, conforme nos reflete Tardif (2014), os professores em formação tendem a repetir em suas salas de aula práticas pedagógicas vivenciadas em cursos de formação inicial e continuada.

O tema do ciclo de modelagem foi Poluição Sonora escolhido pelos próprios professores e desenvolvido em oito ações, conforme quadro que segue: 
Quadro 1 - Descrição das ações desenvolvidas no ciclo de modelagem sobre poluição sonora.

\begin{tabular}{|c|c|}
\hline Ações & Descrição \\
\hline 1) Motivação inicial. & $\begin{array}{l}\text { Discutiu-se coletivamente, em uma roda de conversa, sobre o problema da poluição } \\
\text { sonora, destacando-se os níveis sonoros permitidos por lei de acordo com a Organização } \\
\text { Mundial de Saúde (OMS) e problemas de saúde relacionados ao excesso de barulho. } \\
\text { Após reflexões iniciais, levantou-se as seguintes questões: será que ocorre poluição } \\
\text { sonora na escola? Como melhorar essa situação? }\end{array}$ \\
\hline $\begin{array}{l}\text { 2) Caracterização do } \\
\text { problema. }\end{array}$ & $\begin{array}{l}\text { De maneira coletiva, identificou-se as principais variáveis envolvidas no problema, } \\
\text { foram elas: o local na escola onde seria feito o registro do nível sonoro e o horário em } \\
\text { que os dados seriam coletados, buscando-se entender como essas duas variáveis } \\
\text { poderiam estar relacionadas entre si. }\end{array}$ \\
\hline $\begin{array}{l}\text { 3) Aprofundamento } \\
\text { conceitual. }\end{array}$ & $\begin{array}{l}\text { Por meio de discussões coletivas de resumos conceituais e de pesquisas na internet, } \\
\text { aprofundou-se discussões sobre os conceitos de nível sonoro, intensidade sonora e } \\
\text { unidades de medida } \mathrm{dB} \text { e Watt } / \mathrm{m}^{2} \text {. }\end{array}$ \\
\hline $\begin{array}{l}\text { 4) Planejamento da } \\
\text { pesquisa. }\end{array}$ & $\begin{array}{l}\text { Em pequenos grupos colaborativos (de } 3 \text { a } 5 \text { componentes), discutiu-se sobre } \\
\text { procedimentos necessários para produzir dados sobre o nível sonoro na escola. Para a } \\
\text { coleta de dados empíricos, foi utilizado um aplicativo de celular chamado Sound Meter } \\
\text { disponível gratuitamente na Google Play Store. }\end{array}$ \\
\hline $\begin{array}{l}\text { 5) Produção de } \\
\text { dados empíricos. }\end{array}$ & $\begin{array}{l}\text { Cada grupo colaborativo fez um mapeamento acústico dos diversos ambientes da escola } \\
\text { e das ruas adjacentes. Os estudantes coletaram dados nas salas de aula, diretoria, } \\
\text { secretaria, banheiros, quadra de esporte e nas ruas ao redor da escola. }\end{array}$ \\
\hline $\begin{array}{l}\text { 6) Organização dos } \\
\text { modelos } \\
\text { matemáticos. }\end{array}$ & $\begin{array}{l}\text { Os grupos organizaram os dados produzidos em miniquadros brancos utilizando pincéis } \\
\text { de diferentes cores e múltiplas ferramentas de representação, tais como: diagramas, } \\
\text { tabelas, gráficos, equações. }\end{array}$ \\
\hline $\begin{array}{l}\text { 7) Socialização das } \\
\text { aprendizagens. }\end{array}$ & $\begin{array}{l}\text { Com suporte cognitivo dos modelos matemáticos registrados nos miniquadros, cada } \\
\text { grupo socializou coletivamente com os outros grupos as aprendizagens envolvidas no } \\
\text { ciclo de modelagem e as propostas de soluções ao problema enfrentado. }\end{array}$ \\
\hline 8) Produção escrita. & $\begin{array}{l}\text { Cada grupo colaborativo produziu um relatório escrito para sistematizar a pesquisa } \\
\text { realizada. O relatório deveria detalhar o problema pesquisado, procedimentos } \\
\text { realizados, conceitos envolvidos, resultados alcançados e proposta de soluções. }\end{array}$ \\
\hline
\end{tabular}

Fonte: Adaptado de Souza (2018).

O Quadro 1 organiza o ciclo de modelagem em oito ações: motivação inicial, caracterização do problema, aprofundamento conceitual, planejamento da pesquisa, produção de dados empíricos, organização dos modelos matemáticos, socialização das aprendizagens e produção escrita. Ressalta-se que essas ações não são rígidas, evidentemente, podem variar de acordo com a natureza do cenário educacional em foco; contudo, possibilitaram ao professor um planejamento prévio necessário para evitar "momentos de desconforto" em sala de aula.

Para insumo de dados, utilizou-se nesta pesquisa o questionário aberto como elemento principal. Assim, após participação no ciclo de modelagem, solicitou-se que os professores respondessem a um questionário com seis perguntas abertas, a saber:

Dos fatores profícuos: 
1. Quais potencialidades você destacaria nas tarefas com problemas da realidade em relação ao ensino de física?

2. Quais potencialidades você destacaria nas tarefas investigativas com modelos matemáticos em relação ao ensino de física?

3. Quais potencialidades você destacaria nas tarefas com socialização coletiva das aprendizagens em relação ao ensino de física?

Dos fatores limitantes:

1. Quais desafios você destacaria nas tarefas com problemas da realidade em relação ao ensino de física?

2. Quais desafios você destacaria nas tarefas investigativas com modelos matemáticos em relação ao ensino de física?

3. Quais desafios você destacaria nas tarefas com socialização coletiva das aprendizagens em relação ao ensino de física?

Assim, o corpus de análise constando de textos transcritos foi interpretado por meio de análise textual discursiva em três etapas: unitarização, categorização e metatexto.

Num primeiro instante, da unitarização, realizou-se leitura cuidadosa do corpus de pesquisa para identificar unidades de significado em cada unidade de contexto. "Unitarizar um texto é desmembrá-lo, transformando-o em unidades elementares, correspondendo a elementos discriminantes de sentidos, significados importantes para a finalidade da pesquisa, denominadas de unidades de significado" (MORAES e GALIAZZI, 2016, p. 71).

As unidades de significado geraram subcategorias que foram codificadas por meio de sistema alfanumérico. Num segundo instante, da categorização, tentou-se perceber convergências de significados entre as subcategorias, reagrupando-as em categorias emergentes. Categorizar "corresponde a simplificações, reduções e sínteses de informações da pesquisa, concretizadas por comparação e diferenciação de elementos unitários, resultando em formação de conjuntos de elementos que possuem algo em comum" (MORAES e GALIAZZI, 2016, p. 97).

Por fim, elaborou-se um metatexto com interlocuções empíricas e teóricas resultante de descrições e de interpretações das categorias emergentes para potencialidades e para desafios do ciclo de modelagem. O metatexto representa "[...] sínteses elaboradas pelo pesquisador no sentido de expressar as novas compreensões atingidas em relação ao seu objetivo de pesquisa" (MORAES; GALIAZZI, 2016, p. 111). 


\section{Dos fatores profícuos}

O objetivo desta seção é analisar evidências para refletir sobre como os professores de física perceberam o ciclo de modelagem da poluição sonora com relação ao ensino de física.

Na Fig. 5 ilustra-se as frequências de potencialidades para as tarefas com descrição de problemas da realidade (PDP). Importante ressaltar que as frequências relativas foram calculadas em relação ao número de subcategorias emergentes, quer dizer, em relação às subcategorias identificadas nas unidades de significado a partir das respostas transcritas dos questionários e não aos treze (13) sujeitos participantes da pesquisa. Significa que uma dada subcategoria eventualmente fez parte de mais de uma categoria geral durante a classificação estatística dos resultados.

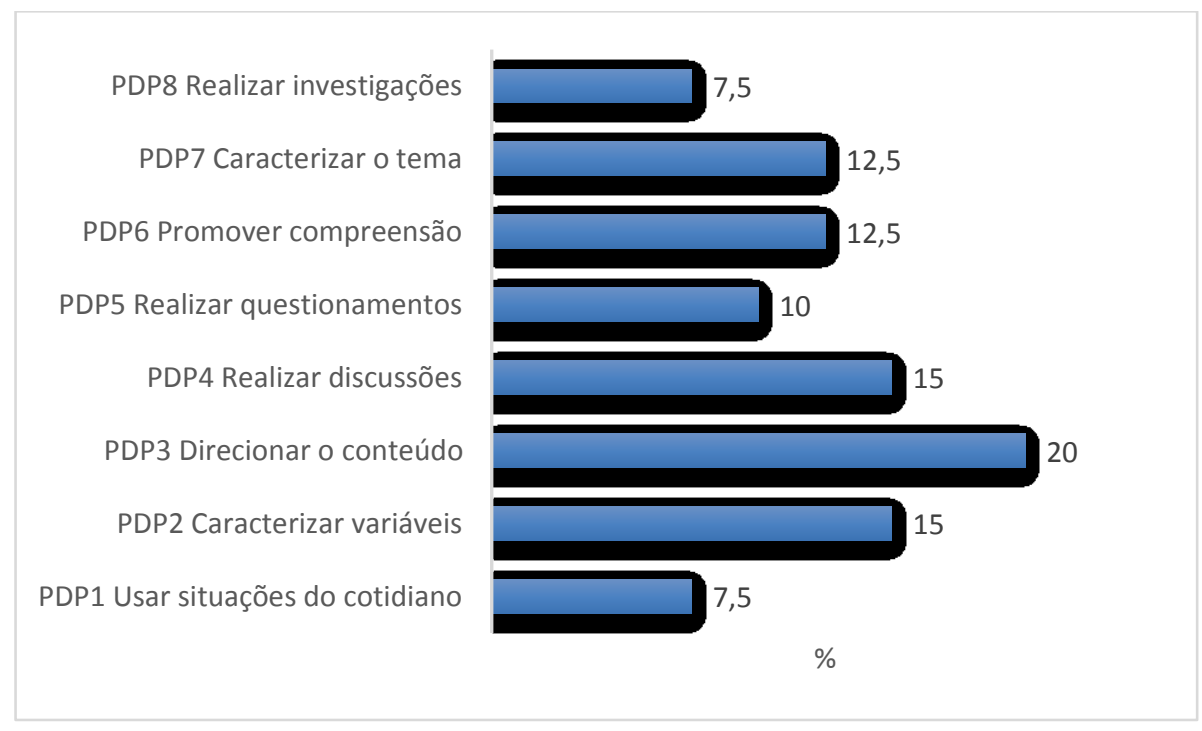

Fig. 5 - Frequências de potencialidades nas tarefas com problemas da realidade. Fonte: Adaptado de Souza (2018).

Infere-se na Fig. 5 que a potencialidade emergente com maior frequência nas tarefas com problemas da realidade foi PDP3, alcançando taxa de 20\% (08 subcategorias), como reforça a fala do sujeito S2: “A escolha da questão foi bastante interessante, pois nela vimos o que seria ideal para trabalhar sobre o tema, a variável que direcione para que tipo de estudo você quer realizar". Para este professor, a possibilidade de escolher um problema de pesquisa favoreceu a investigação de conteúdos de interesse pedagógico. Além disso, sua fala sugere que a descrição de variáveis também contribuiu para direcionar o estudo para determinados assuntos considerados relevantes.

Em seguida, com média frequência, surgem as potencialidades PDP2 e PDP4, cada uma com taxa de 15\% (06 subcategorias). Vejamos o que diz o sujeito S12 com relação à caracterização de variáveis: "Nesta, estão as relações entre variáveis, analiso tal etapa de 
forma positiva, visto que podemos relacionar uma com as outras com o intuito de mobilizar vários subtemas a partir de um mesmo conteúdo". Para este professor, a tarefa de encontrar relações entre as variáveis do problema foi positiva no sentido de permitir eleger diversos subtemas que poderiam ser investigados de maneira coesa dentro de uma mesma situação de aprendizagem.

Ainda com grau médio de frequência, surgem as potencialidades PDP6 e PDP7, cada uma alcançando taxa de 12,5\% (05 subcategorias). A fala do sujeito S3 exemplifica quanto à possibilidade de compreensão de conteúdo: "Foi importante os temas escolhidos e trabalhados em cada aula que tivemos com o professor, pois parecia um simples tema, mas quando foram coletados dados acerca do tema, trouxe um bom entendimento e um conteúdo categórico". Este professor em formação ressalta a importância das tarefas realizadas como forma de "desempacotar" tópicos de estudo dentro de um tema aparentemente simples, promovendo compreensão sobre os conteúdos mobilizados no ciclo de modelagem.

Continuando com média frequência, a potencialidade PDP5 com taxa de 10\% (04 subcategorias), a exemplo da fala do sujeito S13 sobre o levantamento de questões: "Com a questão de modelagem foi muito importante e positivo, quando no grupo buscamos conhecimentos para resolver certa questão proposta pelo tema”. A fase de descrição do problema também foi importante na visão do sujeito S13 não somente para o levantamento de questões, mas também para buscar respostas às questões levantadas pelo grupo.

Por fim, com baixa frequência, emergem as potencialidades PDP1 e PDP8, cada uma com taxa de 7,5\% (03 subcategorias). Vejamos o comentário do sujeito S9 a respeito do uso de situações do cotidiano: "Para mim, é de extrema importância a escolha do tema e sua real discussão (do mesmo). Sendo que o tema seja uma situação do cotidiano do aluno o que facilitará sua discussão". Este professor ressalta claramente em sua fala a importância do uso de situações do cotidiano como facilitadoras do processo de descrição do problema.

Desse modo, os dados evidenciam que, para os sujeitos da pesquisa, a proposição de tarefas com foco em problemas da realidade pode ser favorável predominantemente para direcionar o conteúdo conceitual a ser estudado visando a cumprir a grade curricular de interesse pedagógico, ou seja, destaca-se uma visão conteudista dos professores, talvez devido à própria formação que tiveram até o momento. Pode-se ainda considerar que o uso de problemas da realidade pode ser favorável para realizar várias discussões sobre conceitos, procedimentos e atitudes; para caracterizar variáveis dependentes e independentes; para caracterizar o problema ao especificar suas propriedades gerais e específicas; para promover compreensão significativa sobre conteúdos envolvidos no processo e para propor questionamentos sobre conceitos e procedimentos relevantes. Além disso, infere-se que o uso de problemas da realidade pode ser favorável para realizar investigações em busca de respostas e para estimar o valor das situações do cotidiano enquanto contexto motivacional.

A partir dessas evidências, reflete-se que os fatores profícuos acima destacados para tarefas com foco em problemas da realidade podem estar emergindo principalmente pelo fato 
de que, como ressalta Megowan-Romanowicz (2016), no ciclo de modelagem o problema não é simplesmente imposto pelo professor, mas discute-se sobre o problema de modo a angariar motivações para investiga-lo e diferenciá-lo enquanto um sistema caracterizado por relações conceituais intrínsecas e extrínsecas.

O professor geralmente propõe um problema no inicio da aula. Os estudantes reúnem-se em pequenos grupos colaborativos para encontrar uma solução consensual, então representam seus pensamentos em quadros brancos medindo 60 $\mathrm{cm} \times 80 \mathrm{~cm}$. O professor move-se de grupo em grupo escutando atentamente as discussões enquanto os estudantes discutem sobre o problema e registram suas soluções nos quadros brancos, ocasionalmente, o professor faz um comentário ou levanta uma questão. Quando a discussão em grupo termina, o professor orienta a "sessão de quadro branco" em que a classe inteira compartilha e discute suas soluções (MEGOWAN-ROMANOWICZ, 2016, p. 03, tradução nossa).

Diferentemente do ensino bancário (FREIRE, 2005), em que a aula segue o paradigma do exercício (SKOVSMOSE, 2000) e inicia com a apresentação de definições e de fórmulas, na modelagem matemática o início da aula é a discussão de um problema da realidade. Segue-se uma série de pesquisas em grupos, culminando com a representação das soluções em modelos matemáticos constituídos por múltiplas ferramentas de representação. Essa característica dinâmica e aberta do ciclo de modelagem pode favorecer a emergência de potencialidades como as apresentadas acima.

$\mathrm{Na}$ Fig. 6, ilustram-se as frequências relativas de categorias para potencialidades emergentes no laboratório investigativo de modelos matemáticos (PLI).

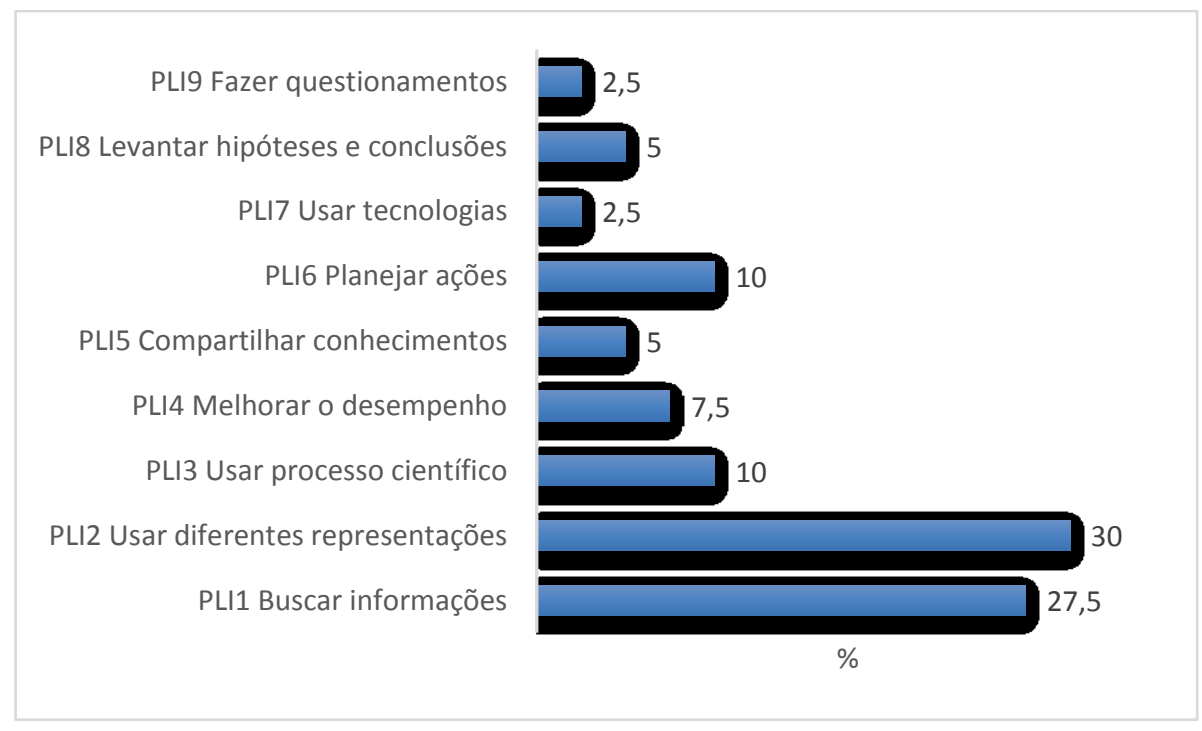

Fig. 6 - Frequência de potencialidades nas tarefas investigativas com modelos matemáticos. Fonte: Adaptado de Souza (2018). 
Infere-se na Fig. 6 que a potencialidade emergente com maior frequência foi PLI2, com 30\% (12 subcategorias). Com referência ao uso de diferentes representações, o sujeito S1 relata: "A livre escolha de como o modelador irá representar os dados que foram coletados e o modelador poderá usar mais de uma representação". Para S1, foi positivo o fato de poder escolher mais de uma ferramenta de representação para organizar os dados coletados oriundos de atividade empírica em um modelo matemático. Ao que parece, a possibilidade de escolher o tipo de ferramenta representativa contribuiu para o aspecto positivo destacado por este professor.

Ainda com elevada frequência, alcançando taxa de 27,5\% (11 subcategorias), surge a categoria PLI1. Quanto à necessidade de planejar e de buscar informações, o sujeito S7 ressalta: "Na produção de dados nós percebemos e pesquisamos as informações de como obtermos informações para satisfazer as nossas necessidades. Para S7, o laboratório de investigação possibilitou elaboração de planos de trabalho em que os professores deveriam pesquisar diferentes maneiras para fazer a investigação científica.

Em seguida, com média frequência, surgem as categorias PLI3 e PLI6, cada uma com taxa de 10\% (04 subcategorias). Com referência ao planejamento de ações, o sujeito S11 sublinha: "São que, a partir do momento que começamos a coletar dados, já temos em mente a real necessidade daquilo que iremos desenvolver". Para este sujeito, o fato de poder planejar procedimentos investigativos antes de efetivamente executá-los constituiu um fator positivo do laboratório de investigação do modelo, pois possibilitou organizar o pensamento e prever eventuais necessidades de materiais e de métodos necessários ao processo investigativo.

Ainda com média frequência, surge a categoria PLI4, com taxa de 7,5\% (03 subcategorias). Quanto à possibilidade de melhorar o próprio desempenho pela pesquisa, o sujeito S3 reforça: "Foi gratificante, pois houve um grande desempenho na turma e partimos em busca de informações de coleta de dados". Nota-se que este professor em formação admite evolução em seu próprio desempenho em função da necessidade de buscar e de compreender as informações necessárias ao laboratório de investigação.

As categorias PLI5 e PLI8 surgem também com média frequência, cada uma com taxa de 5\% (02 subcategorias). Quanto à possibilidade de compartilhar conhecimentos, o sujeito S13 assevera: "Na produção de dados foi muito significativa quando começamos a produzir tabelas, fazer questionamentos, interagir com outros grupos, buscar uma resposta coerente para o problema designado pelo tema". Observa-se que este professor chama atenção para a importância de interagir e de compartilhar informações com outros grupos colaborativos durante a busca de respostas aos questionamentos.

Finalmente, ainda que com baixa frequência, cada uma com taxa de 2,5\% (01 subcategoria), vêm as potencialidades PLI7 e PLI9. Quanto ao uso da tecnologia, o sujeito S8 assevera: "O uso de tecnologias para obter dados e conceitos". Este professor ressalta a 
relevância das tecnologias como ferramentas facilitadoras na obtenção de informações e de conceitos.

Desse modo, pode-se concluir que, para os sujeitos da pesquisa, tarefas investigativas com modelos matemáticos podem favorecer principalmente ao uso de diferentes ferramentas de representação para organizar e para comunicar os dados produzidos. Além disso, infere-se que esse momento do ciclo de modelagem também foi favorável para buscar dados em diferentes fontes de informações. Além disso, a investigação de modelos matemáticos pode promover o uso de processos científicos, o planejamento e a execução de ações investigativas pelos próprios estudantes, o desempenho dos sujeitos modeladores, o compartilhamento de significados atribuídos a conceitos e a procedimentos, o levantamento de hipóteses e de conclusões. É possível ainda concluir que a investigação do modelo matemático representou um momento favorável para o uso de tecnologias e para a realização de questionamentos.

Considera-se que as potencialidades acima realçadas podem ter emergido em função do ambiente de investigação colaborativa propiciado pelo ciclo de modelagem, em que nas palavras de Dye et al. (2013): “os estudantes em grupos pequenos discutem colaborativamente, desenvolvem, debatem e testam um modelo para descrever um fenômeno ou responder a uma questão" (p. 02, tradução nossa). Desse modo, o ambiente investigativo em que os sujeitos da pesquisa foram inseridos, cujas pesquisas foram realizadas na internet, em livros digitais e em livros impressos, possibilitou envolvimentos para a construção e debates sobre modelos matemáticos. Além disso, ressalta-se a importância das tecnologias no processo investigativo, especialmente o uso do smartphone e do notebook durante a coleta e a tabulação dos dados produzidos.

As frequências relativas para potencialidades emergentes nas tarefas com socialização discursiva das aprendizagens (PSD) são mostradas na Figura 7.

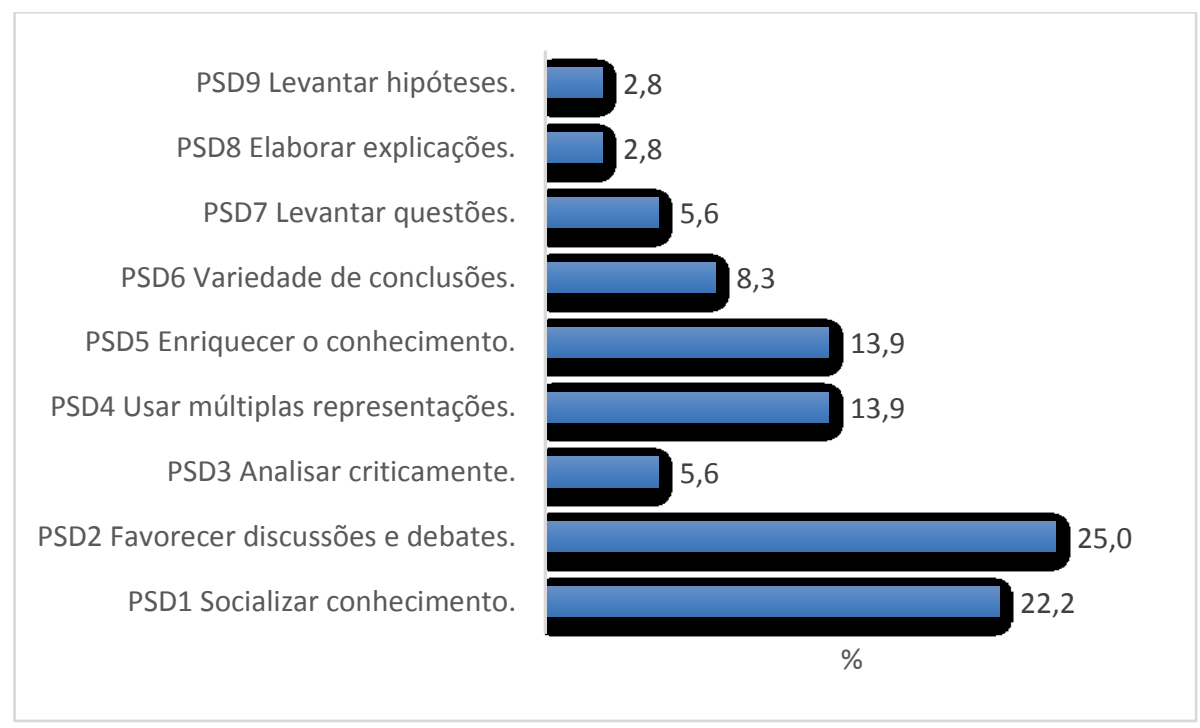

Fig. 7 - Frequência de potencialidades nas tarefas com socialização coletiva das aprendizagens. Fonte: Adaptado de Souza (2018). 
Na Fig. 7, nota-se que a potencialidade PSD2 foi a que alcançou maior frequência, com taxa de 25\% (09 subcategorias). Com relação ao favorecimento de discussões e de debates, o sujeito S2 comenta: "Foi importante a troca de ideias com a turma, as informações expostas de diferentes maneiras pela turma, as discussões entre os colegas enriqueciam ainda mais o conhecimento cientifico sobre o tema". Para este sujeito, o momento em que os grupos discutiam sobre seus modelos matemáticos foi relevante para fomentar a troca de ideias, o que causou certo enriquecimento na compreensão dos conteúdos.

Com frequência ainda elevada, correspondente a uma taxa de 22,2\% (08) subcategorias), surge a potencialidade PSD1, como exemplifica a fala do sujeito S7 com relação à socialização do conhecimento: "É na produção do whiteboard que organizamos matematicamente e compartilhamos as diferentes formas de chegarmos a um objetivo". Para este sujeito, o trabalho com whiteboards [miniquadros brancos] foi importante para a organização do modelo matemático visando à socialização de ações e de pensamentos.

As potencialidades PSD4 e PSD5 surgem com média frequência, cada uma com taxa de 13,9\% (05 subcategorias). Quanto à possibilidade de enriquecer o conhecimento, o sujeito S6 assevera: "É a socialização que amplia o conhecimento...". Nota-se que este sujeito enfatiza que o ato de socializar as pesquisas realizadas pelos grupos colaborativos pode promover um aumento de compreensões sobre conteúdos mobilizados nas discussões.

Ainda com média frequência, alcançando taxa de 8,3\% (03 subcategorias), surge a potencialidade PSD6, como se pode notar no comentário de S8 sobre a possibilidade de obter diferentes conclusões a partir de diversos procedimentos realizados: "Diferentes métodos de exposição e resolução...”. Este sujeito refere que as múltiplas ferramentas de representação para o modelo matemático contribuíram para a obtenção de várias conclusões pelos grupos colaborativos.

Com taxa de 5,6\% (02 subcategorias) e com média frequência, surgem as potencialidades PSD3 e PSD7, como exemplifica a fala de S12 sobre a possibilidade de analisar criticamente os modelos matemáticos: "Através de gráficos, debates, questionamentos, os resultados são expostos para a plateia para fins de reflexão". Este sujeito ressalta que a socialização do modelo matemático com a comunidade de aprendizagem contribuiu para visão crítica sobre a situação modelada.

Por fim, com baixa frequência, surgem as potencialidades PSD8 e PSD9 cada uma com taxa corresponde a 2,8\% (01 subcategoria). Com relação à possibilidade de elaborar explicações, o sujeito S6 assevera: “... surgem questionários contundentes e respostas com boas explicações". Para este sujeito, os questionamentos que vêm à tona no decorrer do processo de análise argumentativa do modelo matemático contribuem para melhorar as explicações dos assuntos debatidos.

Assim sendo, é possível concluir que, para os sujeitos da pesquisa, tarefas com foco na socialização coletiva das aprendizagens são potencialmente favoráveis para o estabelecimento de discussões e de debates e para a socialização do conhecimento 
intergrupos. Esse tipo de tarefa, também foi favorável para o uso de múltiplas ferramentas de representação para expressar e para comunicar os modelos matemáticos, para enriquecer o nível de conhecimento dos sujeitos, para elaborar uma variedade de conclusões a respeito do problema investigado, para fazer análise crítica sobre o tema de pesquisa e para o levantamento de questões. Além disso, esse momento também foi favorável para elaborar explicações e para levantar hipóteses.

No ciclo de modelagem, o processo argumentativo ganha apoio cognitivo dos modelos matemáticos expressos nos miniquadros brancos.

Os estudantes, em pequenos grupos, trabalham no planejamento de atividades para a construção de modelos. Eles compartilham suas ideias por meio dos whiteboards que dirigem as discussões em classe. O papel do instrutor é moderar as discussões e orquestrar atividades apropriadas para o desenvolvimento conceitual (BREWE; KRAMER; O’BRIEN, 2009, p. 013102-2, tradução nossa).

As tarefas com ênfase na investigação de modelos caracterizam-se principalmente por gerar situações de argumentação científica (SOUZA, 2018). Ou seja, é na discussão do modelo que toda a dinâmica argumentativa tem seu início, tornando-se um momento de compartilhamento de significados, pois os modelos matemáticos inscritos ostensivamente nos pequenos quadros brancos podem fortalecer cognitivamente o discurso científico dos grupos colaborativos. Nesse processo, o professor atua no sentido de orientar as discussões dos estudantes com o objetivo de gerar situações de argumentação a partir da estrutura epistêmica do modelo matemático. Tal característica pode ter contribuído para a emergência das potencialidades acima destacadas.

\section{Dos fatores limitantes}

A Fig. 8 mostra as frequências relativas para os desafios referentes às tarefas com descrição de problemas da realidade (DDP).

Na Fig. 8, é possível notar que o desafio DDP1 obteve maior frequência, com taxa de 41,2\% (07 subcategorias), a exemplo do que comenta S1 sobre a dificuldade de escolher problemas ou temas de pesquisa: "A dificuldade de escolher o tema, pois o ciclo de modelagem permite ao modelador ter diversas opções para desenvolver o trabalho". Para este sujeito, houve dificuldade na escolha de assuntos a serem desenvolvidos no ciclo de modelagem, talvez porque, conforme os modeladores levantavam questões sobre o problema inicial, surgiam diversas possibilidades de encaminhamento da pesquisa. Assim, as múltiplas possibilidades de temas de pesquisa configuraram-se como um ponto de desafio a ser superado pelos professores em formação. 


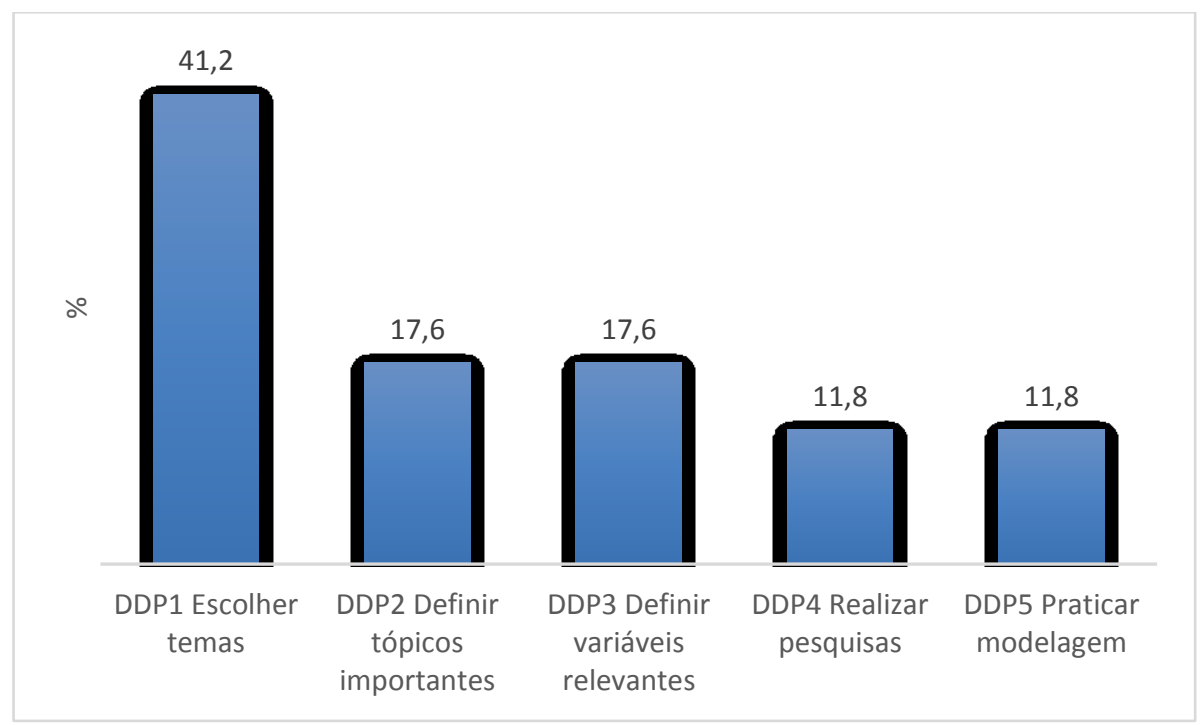

Fig. 8 - Frequências de categorias para desafios nas tarefas com problemas da realidade. Fonte: Adaptado de Souza (2018).

Em seguida, com média frequência, os desafios DDP2 e DDP3, cada um com taxa de 17,6\% (03 subcategorias), como podemos perceber na fala de S4 quanto à definição de variáveis importantes: "Definir as variáveis necessárias e mais importantes a serem discutidas e socializadas". Para o sujeito S4, houve dificuldade para eleger quais variáveis seriam usadas nas ferramentas de representação do modelo matemático (gráficos e tabelas). Tal dificuldade pode ter surgido em função das diferentes possiblidades de variáveis que surgiram por ocasião da descrição do problema.

Por fim, com baixa frequência, os desafios DDP4 e DDP5, cada um com taxa de $11,8 \%$ (02 subcategorias), a exemplo da fala de $\mathrm{S} 10$ a respeito da necessidade de praticar modelagem: "Uma experiência muito produtiva para o processo de ensino, porém é preciso mais práticas", em que este sujeito comenta sobre o desafio de realizar certos procedimentos investigativos, por exemplo, a necessidade de coletar dados empíricos no próprio ambiente escolar, de organizá-los em tabelas e em gráficos e de fazer estimativas.

Desse modo, com base nas evidências acima, é possível concluir que a principal dificuldade apontada pelos professores com relação às tarefas com foco em problemas da realidade foi a necessidade de escolher um tema ou problema para o desenvolvimento do ciclo de modelagem. Além disso, os professores relataram a dificuldade para definir tópicos e a dificuldade para definir variáveis importantes relacionadas ao problema. Outros desafios a serem superados dizem respeito à falta de habilidade para fazer pesquisas e à dificuldade para obter informações, tanto na internet quanto em livros digitais ou impressos.

Reflete-se que um dos fatores que pode ter contribuído para a emergência desses desafios foi que, dificilmente, os professores em formação são inseridos em práticas pedagógicas investigativas, uma vez que o ensino universitário brasileiro ainda possui fortes 
raízes em métodos meramente expositivos, pautados no paradigma do exercício (SKOVSMOSE, 2000). Aliado a isso, a falta de habilidades investigativas, como salientou Heidemann (2015), pode fazer com que alguns estudantes prefiram memorizar conceitos e fórmulas, pois já estão acostumados e, com isso, são levados a rejeitar o trabalho com abordagens ativas, tal como a modelagem matemática.

Considera-se que as dificuldades acima emergentes podem ser amenizadas à medida que os sujeitos são inseridos em ciclos de modelagem. É possível que, conforme participem de atividades com graus crescentes de ação e de tomada de decisão, eles possam adquirir competências para fazer adequadamente a caracterização de problemas, para definir os principais tópicos a serem estudados sobre determinado assunto, para definir variáveis conforme o objetivo da investigação, para consultar fontes de pesquisa alternativas além de livros impressos e da internet, para consultar profissionais especializados e até outros professores da escola.

A frequência relativa das categorias para os desafios referentes às tarefas do laboratório investigativo de modelos matemáticos (DLI) é mostrada na Fig. 9.

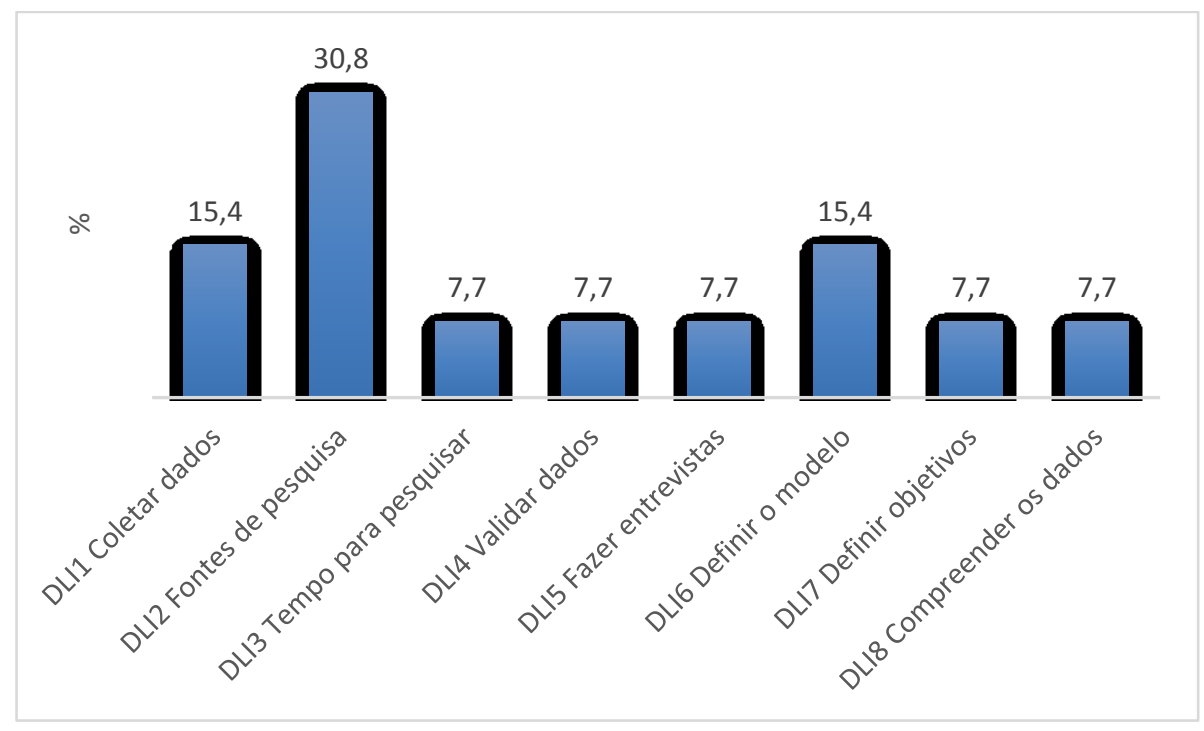

Fig. 9 - Frequências de categorias para desafios nas tarefas investigativas com modelos matemáticos. Fonte: Adaptado de Souza (2018).

Na Fig. 9 é possível inferir que o desafio DLI2 obteve maior frequência, com taxa de 30,8\% (04 subcategorias), sendo a dificuldade mais relatada pelos sujeitos. Sobre a insuficiência de fontes de pesquisa, o sujeito S2 comenta: "Depende do meio em que está sendo pesquisado, pois pode haver ou não informações suficientes". Para este professor, a insuficiência de material para pesquisar depende das condições de infraestrutura educacional disponível. No contexto em que a pesquisa foi desenvolvida, isto é, em uma escola do interior 
do Estado do Pará, a insuficiência de materiais e a infraestrutura inadequada certamente configuraram-se como desafios a serem superados para a realização do ciclo de modelagem.

Em seguida, com média frequência, cada um com taxa de 15,4\% (02 subcategorias), os desafios DLI1 e DLI6. Com relação à dificuldade de elaborar o modelo matemático, o sujeito S6 comenta: "É definir qual modelo será mais fácil para apresentar". Para este sujeito, não foi tarefa fácil escolher a "melhor" ferramenta de representação para compartilhar com os outros sujeitos os modelos matemáticos elaborados pela equipe. Destaca-se que estudantes de um mesmo grupo podem divergir quanto à ferramenta representativa mais adequada para registrar o modelo matemático.

Por fim, com baixa frequência equivalente a uma taxa de 7,7\% (01 subcategoria), os desafios DLI3, DLI4, DLI5, DLI7 e DLI8. Quanto à dificuldade de definir objetivos, o sujeito S11 acrescenta: "São em determinadas ocasiões não saber definir realmente os objetivos a serem alcançados quando se trata de qualidade e quantidade". Para este sujeito, a necessidade de trabalhar com dados qualitativos e com dados quantitativos dificultou a definição de objetivos a serem alcançados. Algumas vezes, os estudantes podem se sentir "perdidos" quanto ao prosseguimento da investigação. Isso acontece quando não conseguem definir com clareza onde pretendem chegar com determinada ação. Em situações desse tipo, a orientação docente é fundamental para que determinado grupo colaborativo possa prosseguir com as ações investigativas.

Considera-se que tais fatores de desafios podem ter como causa o pouco contato com práticas ativas, como se propõe com a modelagem matemática. Hestenes (2010, p. 34) comenta que, no ciclo de modelagem, os estudantes "[...] são introduzidos em ferramentas representacionais e são engajados no uso de ferramentas para estruturar modelos de sistemas reais" (tradução nossa). Como já frisou Heidemann (2015), a inserção de ferramentais representacionais (diagramas, gráficos, equações) é importante porque pode promover expertise em modelagem matemática. Com isso, os estudantes podem levar cada vez menos tempo para pesquisar informações, para aprimorar suas habilidades investigativas, para coletar e validar dados, para melhorar suas técnicas de entrevistas, para definir objetivos e para compreender os dados produzidos.

Antes de fazer as considerações finais, sublinha-se que os sujeitos da pesquisa não apontaram desafios para tarefas com foco na socialização das aprendizagens.

\section{Olhar final}

O objetivo deste artigo foi, por meio de uma abordagem mista envolvendo interpretações quantitativas e qualitativas, compreender os efeitos de um ciclo de modelagem sobre poluição sonora na visão de professores de física.

No Quadro 2, resume-se, de cima para baixo, os fatores profícuos e limitantes em ordem decrescente de frequência para cada momento do ciclo de modelagem. 
Quadro 2 - Fatores profícuos e limitantes em ordem decrescente de frequência de cima para baixo.

\begin{tabular}{|c|c|c|}
\hline Momento do ciclo & Fatores profícuos & Fatores limitantes \\
\hline \multirow[t]{8}{*}{ Descrição de problemas da realidade. } & Usar situações do cotidiano. & Escolher temas. \\
\hline & Caracterizar variáveis. & Definir tópicos importantes. \\
\hline & Direcionar o conteúdo. & Definir variáveis relevantes. \\
\hline & Realizar discussões. & Realizar pesquisas. \\
\hline & Realizar questionamentos. & Praticar modelagem. \\
\hline & Promover compreensão. & --- \\
\hline & Caracterizar o tema. & --- \\
\hline & Realizar investigações. & --- \\
\hline \multirow{9}{*}{$\begin{array}{l}\text { Investigação de modelos } \\
\text { matemáticos. }\end{array}$} & Buscar informações. & Produzir dados. \\
\hline & Usar múltiplas representações. & Fontes de pesquisa. \\
\hline & Usar processo científico. & Tempo para pesquisar. \\
\hline & Melhorar o desempenho. & Validar dados. \\
\hline & Compartilhar conhecimentos. & Fazer entrevistas \\
\hline & Planejar ações. & Definir o modelo. \\
\hline & Usar tecnologias. & Definir objetivos. \\
\hline & Levantar hipóteses e conclusões. & Compreender os dados. \\
\hline & Fazer questionamentos. & --- \\
\hline \multirow[t]{9}{*}{ Socialização das aprendizagens. } & Socializar o conhecimento. & --- \\
\hline & Favorecer discussões e debates. & --- \\
\hline & Analisar criticamente. & --- \\
\hline & Usar múltiplas representações. & --- \\
\hline & Enriquecer o conhecimento. & --- \\
\hline & Variedade de conclusões. & --- \\
\hline & Levantar questões. & --- \\
\hline & Elaborar explicações. & --- \\
\hline & Levantar hipóteses. & --- \\
\hline
\end{tabular}

Fonte: Adaptado de Souza (2018).

No Quadro 2, ao relacionar a quantidade de fatores de potencialidades $\left(n_{f p}=23\right)$, os fatores de desafios $\left(n_{f d}=13\right)$ ao total de fatores (potencialidades + desafios, $n_{f p+d}=36$ ), verifica-se que os fatores de potencialidades corresponderam a aproximadamente $67 \%$ das categorias emergentes, enquanto os fatores de desafios corresponderam a 33\%. Assim, é possível dizer que, na visão dos sujeitos da pesquisa, o ciclo de modelagem mostrou-se predominantemente favorável de ser aplicado, mesmo considerando as contingências educacionais do contexto em que a pesquisa foi realizada.

Desse quadro infere-se que, no momento de descrição do problema real, a potencialidade usar situações do cotidiano surgiu com maior frequência que a potencialidade realizar investigações e o desafio escolher temas surgiu com maior frequência que o desafio 
praticar modelagem. No momento do laboratório de investigação do modelo matemático, a potencialidade buscar informações surgiu com maior frequência que a potencialidade fazer questionamentos e o desafio produzir dados surgiu com maior frequência que o desafio compreender dados produzidos. Por fim, no momento de sessão de discussão, a potencialidade socializar o conhecimento surgiu com maior frequência que a potencialidade levantar hipóteses.

Uma questão que se poderia levantar para o aprofundamento desse estudo é investigar o que apontariam outros sujeitos considerando outros contextos educacionais. Esse questionamento revela as limitações da pesquisa quanto a variáveis referentes ao contexto social em que a investigação foi realizada. Uma vez que não se pretende generalizar os resultados somente com os dados aqui apresentados, faz-se necessário o prosseguimento das discussões, colocando-se outras variáveis no cenário do ciclo de modelagem no ensino de física.

\section{Referências}

AMBRÓSIO, M. O uso do portfólio no ensino superior. Rio de Janeiro: Vozes, 2013 (Livro digital).

BATISTA, M. C. A utilização da experimentação no ensino de física: modelando um ambiente de aprendizagem. 85f. Dissertação (Metrado em Educação para a Ciência e a Matemática) - Universidade Estadual de Maringá, Maringá.

BREWE, E.; KRAMER, L.; O'BRIEN, G. Modeling instruction: positive attitudinal shifts in introductory physics measured with class. Physics Education Research, v. 5, n. 013102, p. 0131021-0131025, 2009.

BUNGE. M. Teoria e realidade. São Paulo: Editora Perspectiva, 1974.

BUNGE. M. Teoria e realidade. Tradução: Gita k. Guinsburg. São Paulo: Perspectiva, 2013.

CRESWELL, J. W.; CLARK, V. P. Pesquisa de métodos mistos. 2. ed. Porto Alegre: Penso, 2013.

DANTE, L. R. Formulação e resolução de problemas de matemática: teoria e prática. São Paulo: Ática, 2011.217p.

DYE, J. et al. The impact of modeling instruction within the inverted curriculum on student achievement in science. Electronic Journal of Science Education, Texas, v. 17, n. 2, p. 119, 2013. 
FLECK, L. Gênese e desenvolvimento de um fato científico. Tradução: Georg Otte; Mariana Oliveira. Belo Horizonte: Fabrefactum, 2010. (Série Ciência, Teconologia, Sociedade).

FREIRE, P. Pedagogia do oprimido. 46. ed. Rio de Janeiro: Paz e Terra, 2005. 213p.

GIERE, R. How models are used to represent reality. Philosophy of Science, v. 71, n. 5, Dec. p. 742-752, 2004.

HEIDEMANN, L. A. Ressignificação das atividades experimentais no ensino de física por meio do enfoque no processo de modelagem científica. 2015. 298f. Tese (Doutorado em Ensino de Física) - Instituto de Física, Universidade Federal do Rio Grande do Sul, Porto Alegre.

HEIDEMANN, L. A; ARAUJO, I. S.; VEIT, E. A. Ciclos de modelagem: uma proposta para integrar atividades baseadas em simulações computacionais e atividades experimentais no ensino de física. Caderno Brasileiro de Ensino de Física, Florianópolis, v. 29, n. Especial 2, p. $965-1007,2012$.

HESTENES, D. Modeling theory for math and science education. In: LESH, R. et al. (Eds.) Modeling student's mathematical modeling competencies. New York: Springer, 2010. p. $13-42$.

HESTENES, D. Toward a modeling theory of physics instruction. American Journal of Physics, Melville, v. 55, n. 5, p. 440-454, may, 1987.

MEGOWAN-ROMANOWICS C. What is modeling instruction? NSTA Reports, p. 3, 2016. Disponível em: <http://www.nsta.org/publications/nstareports.aspx>. Acesso em: 19 out. 2017.

MORAES, R.; GALIAZZI, M. C. Análise textual discursiva. 3. ed. Rio Grande do Sul: Unijui, 2016, 224p.

MOUTINHO, P. E. C. CTS e a modelagem matemática na formação de professores de física. 2007. 115 f. Dissertação (Mestrado em Educação em Ciências e Matemática) - Núcleo Pedagógico de Apoio ao Desenvolvimento Científico, Universidade Federal do Pará, Belém.

SILVA NETO, M. J. Ensino de física pela comparação entre experimento e modelo teórico com uso da modelagem matemática. 2015. 131f. Tese (Doutorado em Educação em 
Ciências e Matemáticas) - Instituto de Educação Matemática e Científica, Universidade Federal do Pará, Belém.

SKOVSMOSE, O. Cenários para investigação. Bolema, Rio Claro, v. 13, n. 14, p. 66-91, 2000 .

SOUZA, E. S. R. Modelagem matemática gerando ambiente de alfabetização científica: discussões no ensino de física. 2018. 237f. Tese (Doutorado em Educação em Ciências e Matemática) - Universidade Federal de Mato Grosso/Universidade Federal do Pará, Belém.

SOUZA, E. S. R. Uma experiência com modelagem matemática para a abordagem de conceitos de física. Acta Scientiae, v. 14, n. 02, p. 309-325, mai./ago. 2012.

TARDIF, M. Saberes docentes e formação profissional. 17. ed. Rio de Janeiro: Vozes, 2014. 325p.

WELLS, M.; HESTENES, D.; SWACKHAMER, G. A modeling method for high school physics instruction. American Journal of Physics, Melville, v. 63, n. 7, p. 606-619, july, 1995. 